\title{
English teachers' motivation for a professional development program: Perspectives of Self-Determination Theory
}

\author{
Basikin \\ Department of English Education, Faculty of Languages and Arts, Universitas Negeri Yogyakarta, \\ Jl. Colombo No. 1 Depok, Sleman, Yogyakarta, 55281, Indonesia
}

\begin{abstract}
The externally driven motivation for a teacher professional development (PD) program is considered less favorable in achieving the desired outcomes than the internally-driven one. When the PD involves a large number of participants, not achieving the outcome leads to a significant waste of time, money, and energy. Unfortunately, this is a common condition in the Indonesian context where teachers go to a PD program due to external motivation. This study examines school English teachers' motivation to attend a PD program in the Yogyakarta province of Indonesia recruited in their district teacher forum (MGMP) meetings. It seeks to answer whether or not externally driven motivation or controlled motivation might become more autonomous. Following the framework of the Self-determination Theory, teachers' motivation was measured using the Teacher Motivation for a Professional Development Scale (TMPDS). Findings suggest that although participants still perceived externally driven attendance by reporting high scores on both introjected regulation $(\mathrm{M}=5.73 ; \mathrm{SD}=2.28)$ and external regulation $(\mathrm{M}=6.51 ; \mathrm{SD}=1.54)$, they also reported high on their intrinsic motivation $(\mathrm{M}=7.58 ; \mathrm{SD}=1.08)$ and the identified regulation $(\mathrm{M}=7.91 ; \mathrm{SD}=1.04)$. Findings indicate that initial extrinsic motivation or controlled could become more intrinsic or autonomous depending on the levels of internalization among the individuals. Findings imply when motivation is external, PD programs should make sure that autonomy supports are available to facilitate internalization.
\end{abstract}

Keywords: Motivation for professional development; teacher motivation; teacher professional development

\begin{tabular}{|ccc|}
\hline \hline First Received: & Revised: & Accepted: \\
26 November 2019 & Mpril 2020 & May 2020 \\
Final Proof Received: & & Published: \\
27 May 2020 & 31 May 2020 \\
\hline How to cite (in APA style): & \\
Basikin. (2020). English teachers' motivation for a professional development program: \\
Perspectives of Self-Determination Theory. Indonesian Journal of Applied Linguistics, \\
10(1),36-45. https://doi.org/10.17509/ijal.v10i1.24982
\end{tabular}

\section{INTRODUCTION}

With the increase in the importance of teacher quality and profession as well as the challenge in the society development (Elchardus, 1994; Hargreaves, 2000), teacher PD programs have been crucial to improve the quality of teacher education (Guskey, 2002). It is also important for education change (Bredeson \& Johanson, 2000). In addition, teacher PD is an opportunity for teachers to help improve their knowledge and practices (Borko, 2004). It can facilitate teachers' quality improvement. It is also an essential effort to improve student learning and schools (Borko, 2004; Opfer \& Pedder, 2011). In addition, a PD program is believed to be able to change both their classroom beliefs and practices as well as students' learning outcomes (Guskey, 2002).

Although teacher PD program is important to enhance teacher quality (Borko, 2004), teachers' classroom practices (Borko, 2004; Guskey, 2002), and student learning outcomes (Borko, 2004; Bredeson \& Johanson, 2000; Guskey, 2002), most literature deals with voluntary participation on a PD program. Therefore, intrinsic motivation is mostly discussed. No sufficient literature in particular examines teachers' externally-driven motivations to attend a PD program and how these intersect with 
potential intrinsic motives. Such a condition also happens in Indonesia, where teachers' attendance at $\mathrm{PD}$ programs is due to the invitation from the government, or the assignment from schools. This is often thought as not favourable. Externally driven attendance is believed to be a poor predictor of successful PD programs. Intrinsic motivation is more desirable and is expected for better outcomes (Deci et al., 1999).

When attendance is externally-driven and volition is restricted, the regulatory process is governed by compliance. The motivation, therefore, is described as controlled (Deci et al., 1991) and is not favourable in terms of achieving optimal achievement. This is the case with Indonesian teachers going to professional development programs that are initiated by the government. Because teachers are considered to lack in the autonomy (Bjork, 2004, 2006) and their attendance is externally driven, their motivation is predicted to be governed by compliance, not by choice. This will raise concerns related to teachers' participation and engagement in the PD programs. Furthermore, when participants' motivation is extrinsic, it will stimulate another problem related to their intention to embrace the innovation introduced through the PD in their subsequent classroom practices. This is the concerns of the society that teachers do not really take on the PD, but go back to their old practices.

\section{The context of the study}

This study was conducted among secondary school English teachers in Indonesia. It deals particularly with their attendance at a professional development program. The teacher PD program investigated in the present study was a training program designed to introduce the genre-based approach to English teaching. In the Indonesian context, this approach is often called a text-based English teaching. It was recommended to be used to teach not only writing skills but all four major skills -speaking, listening, reading, and writing. Although it had been used by some English teachers, the approach was new for most teachers in the country. Through the training initiated by the Ministry of National Education (MoNE), this teaching approach was introduced to all secondary English teachers across the country. The training program was designed to cover techniques in planning and executing the genre-based English teaching, as well as assessing students' learning.

The training of the genre-based English teaching was one of the professional development programs initiated and funded by the Indonesian government to introduce the genre-based teaching of English to schoolteachers. It was aimed to target all secondary school English teachers in Indonesia. Because providing a professional development program to a huge number of participants was costly and took lots of time and energy, ensuring that the participants embrace the newly introduced approach is important.

Teachers' attendance to the training in the present study was non-voluntary. It was due to invitation from the government or assignment from schools as responses to such government invitations. The participants were paid in the form of a lump sum. During the training, the participants were required to stay in the training venue either at government training centres or hotels. All participants' needs of food were provided by the government. The training involved participants in a series of activities such as lectures, discussions, workshops, and peer teaching. Trainers were from both the central offices of the Ministry of National Education and lecturers from universities.

This study analyses participants' motivation to attend a PD program using the Self-Determination Theory (SDT) (Deci \& Ryan, 1985, 2008). It examines the quality of teachers' motivation reflected by the types of regulation reported by the teachers. SDT is used because it is in line with the nature of initial motivation of the participants in attending the training. It is the only motivation theory that claims the possibility of extrinsic motivation to change into more intrinsic types, given internalisation happens.

\section{Externally-driven motivation and internalization:} SDT perspectives

SDT has proposed important claims by offering alternative perspectives to deal with motivation, especially the extrinsic motivation. It allows the possibility to deal with not only voluntary participation, but also non-voluntary participation signalled by the absence of volitional condition or choices. Two important claims of SDT are instrumental in the conduct of the present study. They argued that i) motivation is multidimensional, and ii) motivation sits on a single self-determination continuum, from controlled to more autonomous types of motivation. They are considered important features that differentiate SDT from other theories of motivation (Deci \& Ryan, 1985, 2000, 2008).

Unlike other theories that consider motivation as unidimensional, focusing on the levels or amount of motivation people have for a particular behaviour (Bandura, 1989, 1994; Wigfield \& Eccles, 2000), SDT looks at motivation as multidimensional (Deci \& Ryan, 1985, 2008). It looks at not only the amount or levels of motivation one has, but also the types or quality of the motivation. It further states that the quality of motivation predicts the outcomes better (Vansteenkiste et al., 2009). The quality is determined by the degree of internalization that is reflected by the types of regulatory processes experienced by an individual.

When looking at the quality of motivation, SDT classifies motivation as autonomous and controlled motivation, with the earlier type is considered more 
favourable than the later one. SDT believes in people differences in not only the quantity (highly vs lowly motivated), but also the quality of their motivation (well vs poorly motivated). Combining both dimensions, researchers arrive at the four clusters of motivation of 1) good quality motivation (high autonomous - low controlled motivation), 2) poor quality motivation (low autonomous - high controlled motivation), 3) high quantity motivation (high autonomous - high controlled motivation), and 4) low quantity motivation (low autonomous - controlled motivation) (Vallerand, 1997).

In terms of extrinsic motivation, SDT differs from the common belief that extrinsically motivated behaviours are behaviours performed due to external forces in absence of the self-regulation. SDT believes that there exist certain regulatory processes that lead to different types of self-regulation. SDT categorizes such two regulatory processes as introjection and integration. On the one hand, introjection refers to a situation when people take in or regulate a value without embracing as their own. On the other hand, integration is referred to as a process of internalization when people accept or regulate the value of an activity by assimilating it with their own personal self (Deci et al., 1994; Deci \& Ryan, 2008). It is these regulatory processes that determine the types and quality of motivation. The introjection results in more controlled types of motivation, while integration results in the more autonomous types of motivation.

Based on the two regulatory processes, SDT researchers classified four types of regulation regarding externally driven activities or behaviours (Deci \& Ryan, 1985; Vallerand et al., 1992). The first two types, the external and introjected regulations, are resulted from the introjection process that occurs within an individual. The other two types, the identified and integrated regulations, are resulted from the integration process within an individual. From the more external to more internal types of regulation, they classify the extrinsic motivation into external regulation, introjected regulation, identified regulation, and integrated regulation (Figure 1), see Deci and Ryan (1985) for detailed explanation on the regulation types.

Another important proposal made by SDT is that intrinsic and extrinsic motivation sits on a single self-determination continuum, adding amotivation at the opposite end of intrinsic motivation (Deci \& Ryan, 1985). Certain behaviour, therefore, can be intrinsically motivated, externally motivated or amotivated. The linearity of the types of motivation is often signalled by the simplex-like pattern of correlation among the regulation types, with adjacent types show higher correlation compared to types of motivation situated further away on the continuum.

In addition, SDT researchers have categorized motivation into autonomous motivation covering both intrinsic motivation and highly regulated extrinsic motivation - identified and integrated regulations, and controlled motivation, covering external and introjected regulations (Deci \& Ryan, 1985, 2000, 2008). As opposed to autonomous motivation which is defined as one's internalized desire to do something that derive from personal self, controlled motivation is one's desire to do an activity that sources from other than personal self. It is derived from the existence of external contingencies. Combined together with amotivation - a condition when an individual fails to perceive the contingency between their action and the outcomes - and intrinsic motivation, there are six types of regulation in the continuum - amotivation, external regulation, introjected regulation, identified regulation, integrated regulation, and intrinsic motivation (Deci \& Ryan, 2000; Guay et al., 2003).

\section{Figure 1}

Types of Extrinsic Motivation Resulted from Two Regulatory Processes

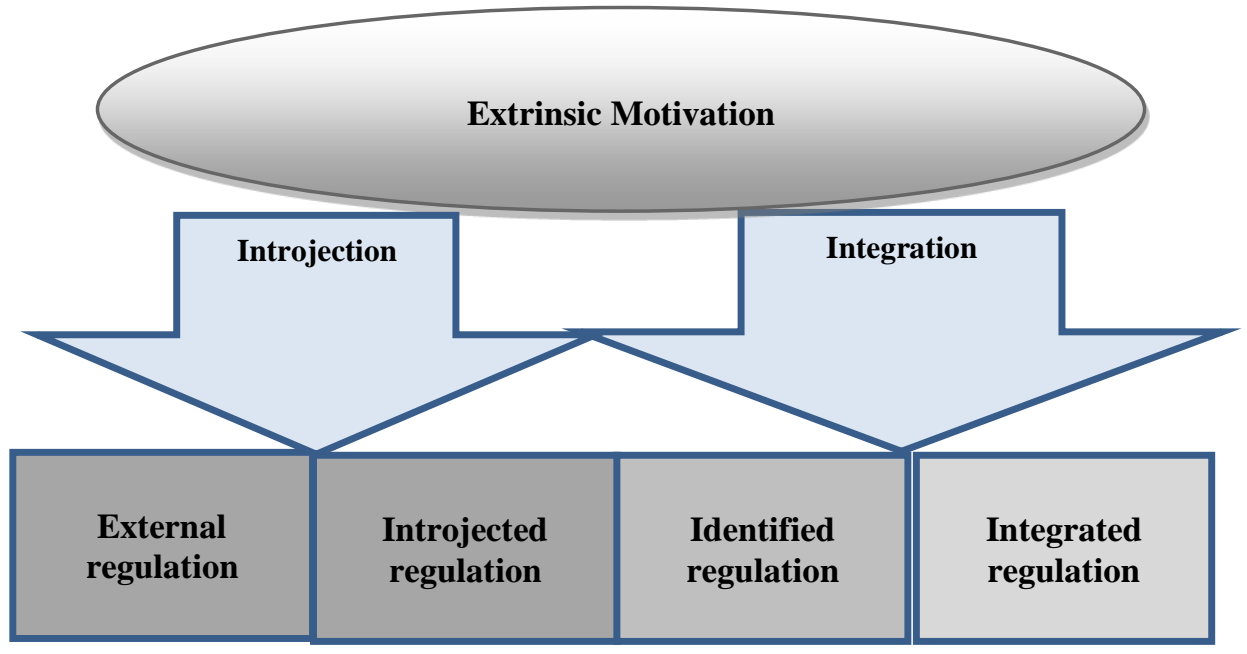


Considering such single continuum, certain extrinsic motivation can be either autonomous or controlled, depending on the degree of internalization an individual experienced - a process by which individuals relate external drives into self attributes or values (Gagne \& Deci, 2005). It is the types or styles of the regulatory processes that determine the levels of internalization.

SDT also suggests the possibility to facilitate internalization. One way that is proposed is by presenting autonomy supports (Grolnick \& Ryan, 1989). In practice, internalization can be promoted by presenting a) meaningful rationale, b) acknowledgement of one's perspectives, and c) presentation of choice rather than control (Deci et al., 1994). In addition, internalization will also be facilitated if the behavers believe that the activities satisfy their needs for competence, autonomy and relatedness (Deci et al., 2001; Deci et al., 1996; Deci et al., 1991; Ryan \& Deci, 2017, 2019).

More recent research using SDT, however, has suggested a slightly different classification of motivation types. Some researchers combined the identified and integrated regulation into identified regulation (Fernet et al., 2008; Pelletier et al., 1995). Some other researchers even come up with different types of motivation like self-determined and nonself-determined extrinsic motivation (Gillet, Vallerand, \& Lafreniere, 2012), high versus poor quality motivation and high versus low quantity motivation (Vansteenkiste et al., 2009). Such differences in expressing the types of motivation are based on empirical data found by the respective researchers with specific groups of samples.

\section{METHOD}

\section{Research participants}

Data were collected from 210 junior high school English teachers in Yogyakarta Special Territory of Indonesia recruited directly by going to teacher forum meetings in four regencies and municipality. Only teachers who had completed the genre-based English teacher training and had been in the teaching profession for five years or longer were eligible to be the participants. The description and distribution of the sample is presented in Table 1.

Table 1

Sample Description and Distribution

\begin{tabular}{llrc}
\hline Demographic variables & Categorical groups & $\mathbf{N}$ & \% \\
\hline Gender & Male & 54 & 25.7 \\
& Female & 156 & 74.3 \\
Education Background & Masters in English teaching & 44 & 20.9 \\
& Bachelor in English teaching & 142 & 67.6 \\
& Diploma in English teaching & 19 & 9.04 \\
& Others & 4 & 1.9 \\
& Missing & 1 & 0.45 \\
Years in teaching & 5-15 years & 111 & 52.9 \\
& $>15$ & 99 & 47.1 \\
Certification status & & & \\
& Certified teachers & 173 & 82.4 \\
Schools & Non-certified teachers & 37 & 17.6 \\
& & & \\
& Public & 184 & 87.6 \\
Districts & Private & 26 & 12.4 \\
& & & \\
& Yogyakarta & 30 & 14.3 \\
& Sleman & 56 & 26.7 \\
& Bantul & 35 & 16.7 \\
& Kulonprogo & 44 & 20.9 \\
& Gunungkidul & 45 & 21.4 \\
\hline
\end{tabular}

\section{Research instruments and technique of data collection}

Data were collected using the Teacher Motivation for Professional Development Scale (TMPDS) adapted from The Work Tasks Motivation Scale for Teachers (WTMST) (Fernet et al., 2013; Fernet, et al., 2017; Fernet et al., 2008). Adaptation was done mainly by changing the wording to fit with the context of the present study. The comparison between items used in
Fernet's WTMST and TMPDS and the adaptation can be seen in Table 2 .

There were five-subscales in TMPDS with three statements in every subscale. The subscales address different types of regulation arranged from the intrinsic motivation, followed by the most autonomous or least controlled to the less autonomous or most controlled, and ended with amotivation. Altogether the five subscales covered 
the intrinsic motivation, identified regulation, introjected regulation, external regulation and amotivation.

To collect more comprehensive responses, the scale was accompanied with one open ended question asking the participants to list three reasons for attending the PD program. The purpose of this question was to provide more insights about participants' motivation to attend the PD program.

Table 2

Comparison between WTMST and TMPDS and the Adaptation

\begin{tabular}{|c|c|c|}
\hline Factors & Fernet's WTMST & TMPDS \\
\hline Intrinsic motivation & $\begin{array}{l}\text { Because it is pleasant to carry out this task. } \\
\text { Because I find this task interesting to do. } \\
\text { Because I like doing this task. }\end{array}$ & $\begin{array}{l}\text { Because it was pleasant to attend this training. } \\
\text { Because I found this training interesting to do. } \\
\text { Because I liked doing the activities in the } \\
\text { training. }\end{array}$ \\
\hline Identified regulation & $\begin{array}{l}\text { Because it is important for me to carry out this } \\
\text { task. } \\
\text { Because this task allows me to attain work } \\
\text { objectives that I consider important. } \\
\text { Because I find this task important for the } \\
\text { academic success of my students. }\end{array}$ & $\begin{array}{l}\text { Because this training was important for me to } \\
\text { carry out my teaching duties. } \\
\text { Because this training allowed me to attain } \\
\text { work objectives that I consider important. } \\
\text { Because I found this training important for the } \\
\text { academic success of my students. }\end{array}$ \\
\hline Introjected regulation & $\begin{array}{l}\text { Because if I don't carry out this task, I will } \\
\text { feel bad. } \\
\text { Because I would feel guilty not doing it. } \\
\text { To not feel bad if I don't do it. }\end{array}$ & $\begin{array}{l}\text { Because if I did not attend this training, I } \\
\text { would feel bad. } \\
\text { Because I would feel guilty if I did not attend } \\
\text { the training. } \\
\text { Because I did not want to feel bad. }\end{array}$ \\
\hline External regulation & $\begin{array}{l}\text { Because my work demands it. } \\
\text { Because the school obliges me to do it. } \\
\text { Because I'm paid to do it. }\end{array}$ & $\begin{array}{l}\text { Because my duties demanded me to attend to } \\
\text { it. } \\
\text { Because my school oblige } d \text { me to do it. } \\
\text { Because I was paid to do it. }\end{array}$ \\
\hline Amotivation & $\begin{array}{l}\text { I don't know, I don't always see the relevance } \\
\text { of carrying out this task. } \\
\text { I used to know why I was doing this task, but I } \\
\text { don't see the reason anymore. } \\
\text { I don't know, sometimes I don't see its } \\
\text { purpose. }\end{array}$ & $\begin{array}{l}\text { I did not know. I did not see the relevance of } \\
\text { going to this training. } \\
\text { I did not know the reasons of doing this. } \\
\text { I did not know. I did not understand the } \\
\text { purpose of going to the training. }\end{array}$ \\
\hline
\end{tabular}

\section{Data analysis}

Quantitative data were analysed using the descriptive statistics exploring the means, standard deviations, and the frequency of participants' responses. Although data were collected from 210 participants, not all responses were included in the analysis. Only 202 responses were analysed with 8 responses were excluded due to non-random missing data and patterned responses found in the preliminary data analysis. To assess the simplex-like correlation pattern in the data, the Pearson's Product moment correlation was used. The investigation of this correlation pattern is important in relation to the selfdetermination theory that is used to frame this study. It is useful to provide explanation about the assumption on the single continuum and linearity of the types of regulation in the continuum.

Qualitative data were analysed using the theory-driven content analysis adapted from Chi's verbal analysis (Chi, 1997). At the centre of the analysis is an effort to analyse qualitative data in a more objective and quantifiable way. In this analysis, the researcher extracted information from participants' answers into themes, and calculated the occurrence or co-occurrence of themes within the answers. These themes were then interpreted according to the categories relevant with the theory used to frame the study i.e. self-determination theory.

If all 202 participants listed three reasons like what was asked the maximum number of responses would be 606 . However, not all participants answered the question, and not all of those who answered the question listed three reasons. Some participants only provided two reasons and some other only provided one reason. At the end of the analysis, there were 426 responses. Results from this analysis was presented in Table 6.

\section{RESULTS AND DISCUSSION}

\section{Teacher's motivation to attend a PD program}

Quantitative data show that motivation is generally high and belongs to the autonomous types of motivation. It is implied in the mean scores of the intrinsic motivation and identified regulation which are well above the middle point on a ten-point scale.

Because motivation lies on one single continuum (Deci \& Ryan, 2008; Deci et al., 1991), looking at the correlation among the types of regulation in the continuum is important. This 
correlation in the data provides evidence whether the claim of single continuum nature of motivation is supported. The correlation among the types of the regulation is presented in Table 4.

Table 3

Means and Standard Deviations of Teacher Motivation for a Professional Development Scale (TMPDS)

\begin{tabular}{lccc}
\hline Factors & $\mathbf{N}$ & $\mathbf{M}$ & SD \\
\hline Intrinsic Motivation & 202 & 7.58 & 1.08 \\
Identified Regulation & 202 & 7.91 & 1.04 \\
Introjected Regulation & 202 & 5.73 & 2.28 \\
External regulation & 202 & 6.51 & 1.54 \\
Amotivation & 202 & 1.99 & 2.17 \\
\hline
\end{tabular}

Table 4

Correlations among Types of Regulation of Teacher Motivation for Professional Development Scale (TMPDS)

\begin{tabular}{|c|c|c|c|c|c|}
\hline & IM & ID & IR & ER & Am \\
\hline $\begin{array}{l}\text { Intrinsic } \\
\text { Motivation (IM) }\end{array}$ & 1 & $.467^{*}$ & $.234_{*}^{*}$ & $.396^{*}$ & -.114 \\
\hline $\begin{array}{l}\text { Identified } \\
\text { Regulation (ID) }\end{array}$ & & 1 & -.020 & $\begin{array}{r}.216^{*} \\
*\end{array}$ & $\begin{array}{r}- \\
.508^{*} \\
*\end{array}$ \\
\hline $\begin{array}{l}\text { Introjected } \\
\text { Regulation (IR) }\end{array}$ & & & 1 & $.397^{*}$ & $.283^{*}$ \\
\hline $\begin{array}{l}\text { External } \\
\text { Regulation (ER }\end{array}$ & & & & 1 & $.143^{*}$ \\
\hline $\begin{array}{l}\text { Amotivation } \\
(\mathrm{AM})\end{array}$ & & & & & 1 \\
\hline
\end{tabular}

\section{Findings from the open-ended item}

As discussed in the section about the research instrument, there is one open-ended question in the questionnaire. It asks the participants' responses about three most important reasons for attending the PD program. The detailed information about the emerging themes and participants' responses are in Table 5 .

As shown in Table 5, big number of responses indicate that teachers in the sample reported both the external regulation and intrinsic motivation. When observed at a glance, it looks contradictory. When reflected in the reality, however, such findings are expected. The initial motivation of the teachers is indeed external. Their attendance to the PD program is regulated by external factor.

Findings imply that, although reasons for attending the PD was initially extrinsic, the participants were able to identify the PD as part of themselves and find enjoyment from the PD. High scores on both types of regulation suggest that participants motivation are more autonomous. In other words, the regulatory process experienced by the participants is more of the integration. In terms of intrinsic motivation, the item 'I found it interesting to do the training' was rated the highest, with $\mathrm{M}=7.90$ and $\mathrm{SD}=1.10$. This is an interesting response, since participants' interest in the training can imply at least two things. First, such an interest is purely about the training which implies that this is purely intrinsic. However, the fact that the training was not voluntary and involved some positive reinforcement in the forms of both incentives and staying in a good hotel and good foods might raise an issue regarding whether the motivation was intrinsic or extrinsic. Besides, being away from the schools could mean positive things that can add participants to the training. If that is the case, this seemingly intrinsic type of motivation could in reality be extrinsic.

\section{Table 5}

Responses and Themes from the Qualitative Data

\begin{tabular}{|c|c|c|}
\hline Types of motivation & $\mathbf{N}$ & Sample responses \\
\hline Intrinsic motivation & $\begin{array}{l}78 \\
(18 \%)\end{array}$ & $\begin{array}{l}\text { I liked going to the training. } \\
\text { I enjoyed the activities in the training. } \\
\text { I liked sharing with my colleagues. } \\
\text { I am interested in new ideas. }\end{array}$ \\
\hline Identified regulation & $\begin{array}{l}224 \\
(53 \%)\end{array}$ & $\begin{array}{l}\text { It helped me improve my teaching. } \\
\text { It gave me new knowledge that was useful for my teaching. } \\
\text { Genre-based teaching could help improve my students' learning. }\end{array}$ \\
\hline Introjected regulation & $\begin{array}{l}49 \\
(12 \%)\end{array}$ & $\begin{array}{l}\text { I felt bad if I did not go to the training. } \\
\text { I felt guilty if I did not attend the training. } \\
\text { I felt obliged to go to the training. }\end{array}$ \\
\hline External regulation & $\begin{array}{l}67 \\
(16 \%)\end{array}$ & $\begin{array}{l}\text { Because the principal asked me to go. } \\
\text { I was paid partly to do the training. } \\
\text { My principal would get angry if I did not go. }\end{array}$ \\
\hline Amotivation & $\begin{array}{l}8 \\
(0.2 \%)\end{array}$ & $\begin{array}{l}\text { I did not know why I was on the training. } \\
\text { I did not see the relevance of the training, (I would finish my teaching duty } \\
\text { in few soon). }\end{array}$ \\
\hline
\end{tabular}


The possibility of having an extrinsic motivation in relation to PD was supported by the item that was reported as second highest, 'It was pleasant to attend the training', with $\mathrm{M}=7.48$ and SD $=1.61$. This again was about participants' evaluation about the pleasure that the training had provided. The only item that addressed the activities in the training, I liked doing the activities in the training, was rated the lowest among the three, with $\mathrm{M}=7.39$ and $\mathrm{SD}=$ 1.45 .

Participants responses to the identified regulation items were surprisingly positive, considering that the initial motivation is external. The average mean score of the three items was 7.91. Among the three items, the item related to the importance of the training to help students achieve their academic success was rated the highest, with $\mathrm{M}$ $=8.23$ and $\mathrm{SD}=.93$. It was then followed by the participants' recognition that the training was important to help teachers carry out their teaching duties $(M=7.93 ; \mathrm{SD}=1.65)$, and the ability of the training to help teachers to attain important work objectives $(\mathrm{M}=7.57 ; \mathrm{SD}=1.41)$. Participants' responses to the three items revealed that the participants had internalized the training as parts of themselves, though they still considered it as a means of achieving certain objectives within their professional life - for example to improve their teaching or to help students' learning.

Apart from the high scores reported by the participants in terms of the identified regulation and intrinsic motivation, items related to both external and introjected regulations were also reported high by the participants. It means that the participants still perceived the presence of consequences for attending or not attending the PD - both consequences from outside and inside themselves. Consequences from outside the participants might be in the forms of rewards and sanctions, while those from inside the participants might be in the forms of feeling comfortable or save when attending; or feeling guilty or sad when not attending the PD.

Although it sounded strange, such high scores on both controlled and autonomous types of motivation reported by participants in this sample still fit with the researcher's expectation. The teacher PD program investigated in this research, the training of the genre-based English teaching, was initiated by the Ministry of National Education (MoNE). Teachers' participants were due to their compliance to the invitation from the either the central or local office of MoNE, or assignment from the school principal. Therefore, the participants still perceived compliance as the battery of their regulatory processes, thus resulting in either external or introjected regulation. However, what was good about these dual responses was that when participants reported high scores on both controlled and autonomous types of motivation, the scores of the controlled types were lower than that of the autonomous types of motivation. This implied that there were indeed high levels of internalization among the participants.

The fact that there were high levels of internalization process signalled by high scores reported on identified regulation were also supported by findings from the qualitative data collected using the open-ended question. From 197 participants responding to the question, there were 426 responses. All the responses were then classified into five different themes based on five types of motivation proposed by the SDT. Among the five themes, identified motivation was on top of the rank in terms of the frequency of participants mentioned, with 53\% of the total responses. Responses belong to the intrinsic motivation (18\%) was second in the rank. It was then followed by external regulation $(16 \%)$ and introjected regulation (12\%). Only few responses under amotivation $(0.2 \%)$ was reported. These findings gave emphasis on the presence of internalization process among the participants.

\section{Violation of the simplex-like correlation patterns and single continuum of motivation}

Although findings confirmed the internalization processes, the present study revealed two important differences compared to findings from other studies using the SDT framework. The two differences concerned the simplex-like correlation pattern and the continuous nature of the motivation continuum. These differences were important in terms of SDT theory that has been established. Different findings function as a means to verify the theory to address more specific and a more complex context of participants.

Majority of research in motivation using SDT has reported simplex-like correlation pattern among the factors within the scale (Lafrenière et al., 2012; Mallett et al., 2007; Martens \& Webber, 2002; Pelletier et al., 2013). This pattern suggests that each construct is correlated to the next in a linear sequence. Further, it also suggests that the correlation is higher between adjacent constructs than with the distant constructs. Identification of a simplex-like pattern supports the SDT proposal that motivation lies on a single continuum of controlled and autonomous motivation with the least autonomous type of motivation at one end and the most autonomous at the other (Deci \& Ryan, 2000, 2008).

Findings form this study, however, suggest a violation in both the simplex-like correlation patterns and the single continuum of self-regulation (see Table 4). Simplex-like correlation patterns suggested by SDT suggest that adjacent constructs correlate higher than constructs further away in the continuum. The correlation between intrinsic motivation and identified regulation, for example, is higher than that of intrinsic motivation and introjected regulation, or external regulation or even amotivation. Findings, however, did not confirm such patterns. Deviation 
from the simplex-like pattern, in particular, was related to the external regulation. For example, the correlation between intrinsic motivation and external regulation is higher than that of the intrinsic motivation and introjected regulation. This was not true according to SDT. Theoretically speaking, when simplex-like patterns was confirmed, the correlation between intrinsic motivation and external regulation should be lower, because they are situated further away on the continuum. This was not the case with the present study.

A possible solution relates to the nature of participants' initial motivation to attend the investigated PD program, which was external. Although the participants experienced internalization through the integration process, thus reported high scores on the more autonomous types of motivation, they were still reported that they attended the PD program due to external factors. They reported high scores on the external regulation which belongs to a more control type of motivation in addition to the autonomous types of motivation. This yielded higher correlation between external regulation and both identified regulation and intrinsic motivation.

Another possible answer related to the earlier suspicion was that the autonomous motivation reported by the participants was not really intrinsic. The participants reported that they like the training, or that the training was pleasant, was not because the training itself, but because everything accompanying the training. For example, the participants liked the fact that during the training they stayed in a hotel, or because they were paid, or because they could meet friends, or even because they did not have to teach while they were attending the training. Though the responses superficially related to the intrinsic motivation - because they contained the words such as like, pleasant, happy, interested and other corresponding words - it was actually external. What really attracted to the participants was the benefits they got from attending the training.

In addition, the deviation from the single continuum of motivation as proposed by the SDT was shown by the result of the factor analysis. From five factors in the SDT construct, only four factors emerged based on the results of Exploratory Factor Analysis (EFA) using the Maximum Likelihood extraction and Varimax rotation. Unlike most SDT scales that distinguished the intrinsic motivation from identified regulation and situated them on a linear sequence of a continuum, the present study suggested that participants reported an overlap between intrinsic motivation and identified regulation. They did not differentiate the two factors in the construct but perceived them as a single factor (Table 6).

Another evidence of the deviation from the single continuum was the fact that although both autonomous regulations - the intrinsic motivation and identified regulation - were reported high by the participants with $\mathrm{M}=7.58$ and 7.91 , the participants also reported high on both introjected and external regulation with $\mathrm{M}=5.73$ and 6.51 (see Table 3).

Table 6

Results of Exploratory Factor Analysis

\begin{tabular}{lcccc} 
& \multicolumn{3}{c}{ Factors } & \\
& AM & ER & IR & ID \\
\hline Item 1 & & & & .627 \\
Item 2 & & & & .518 \\
Item 3 & & & & .636 \\
Item 4 & & & & .436 \\
Item 5 & & & & .502 \\
Item 6 & & & .868 & .445 \\
Item 7 & & & .772 & \\
Item 8 & & & .678 & \\
Item 9 & & .594 & & \\
Item 10 & & .474 & & \\
Item 11 & & .964 & & \\
Item 12 & & & & \\
Item 13 & .772 & & & \\
Item 14 & .838 & & & \\
Item 15 & .874 & & & \\
\hline
\end{tabular}

Such findings were supported by the findings from qualitative data, particularly in terms of the overlaps between more autonomous types of motivation and controlled types of motivation. Quite many participants reported answers reflecting more than one type of regulation when asked to list three reasons for attending the PD. For example, many participants reported both intrinsic motivation and identified motivation. Even some participants who reported that they were intrinsically motivated or reported the identified regulation type, also reported responses that reflect the external regulation type of motivation.

\section{CONCLUSION}

There are three important findings that the present study serves in terms of externally driven motivation among sample of school English teachers in one province of Indonesia. First, it provides evidence supporting the SDT suggesting that teachers with initial extrinsic motivation reported reasons for attending the PD as more autonomous. Among the five types of motivation they asked to rate, the reported highest in the identified regulation and intrinsic motivation, which belong to the more autonomous types of motivation. However, because the motivation was indeed externally driven, the participants still reported the more controlled types of motivation as high, although still lower than the autonomous types. Second, such findings however also suggest an overlap among types of motivation reported by the participants - for example, a number of participants reported high autonomous and controlled types of motivation. Such overlaps did not confirm the single continuum of motivation proposed by SDT researchers. When motivation really sit on a single continuum, there will be no possibility for the same individual to report high on both autonomous 
and controlled types of motivation. Third, findings of the present study did not confirm the simplex-like correlation patterns. Some adjacent factors did not show higher correlation compared those situated further away on the continuum.

\section{REFERENCES}

Bandura, A. (1989). Human agency in social cognitive theory. American Psychologist, 44, 1175-1184. https://psycnet.apa.org/doi/10.1037/0003066X.44.9.1175

Bandura, A. (1994). Self-efficacy. In V. S. Ramachaudran (Ed.), Encyclopedia of human behavior (Vol. 4, pp. 71-81). New York Academic Press.

Bjork, C. (2004). Decentralisation in education, institutional culture and teacher autonomy in Indonesia. International Review of Education, 50, 245-262. https://doi.org/10.1007/s11159004-2622-6

Bjork, C. (2006). Transferring authority to local school communities in Indonesia: Ambitious plans, mixed results. In C. Bjork (Ed.), Educational Decentralization: Asian Experiences and Conceptual Contributions (pp. 129-148). Springer.

Borko, H. (2004). Professional development and teacher learning: Mapping the terrain. Educational Research, 33(8), 3-15. https://doi.org/10.3102\%2F0013189X0330080 03

Bredeson, P. V., \& Johanson, O. (2000). The school principal's role in teacher professional development. Journal of in-service education, 26(2), 285-401. https://doi.org/10.1080/13674580000200114

Chi, M. T. H. (1997). Quantifying qualitative analyses of verbal data: A practical guide. Journal of the Learning Sciences, 6(3), 271315. https://doi.org/10.1207/s15327809j1s0603_1

Deci, E. L., Eghari, H., Patrick, B. C., \& Leone, D. R. (1994). Facilitating internalization: The Self-Determination Theory perspective. Journal of Personality, 62(1), 119-142. https://doi.org/10.1111/j.14676494.1994.tb00797.x

Deci, E. L., Koestner, R., \& Ryan, R. M. (1999). A meta-analytic review of experiments examining the effects of extrinsic rewards on intrinsic motivation. Psychological Bulletin 125, 627-668.

https://psycnet.apa.org/doi/10.1037/00332909.125.6.627

Deci, E. L., \& Ryan, R. M. (1985). Intrinsic motivation and self-determination in human behavior. Plenum.
Deci, E. L., \& Ryan, R. M. (2000). The 'what' and 'why' of goal pursuits: Human needs and the self-determination of behavior. Psychological Inquiry, 11, 227-268.

https://doi.org/10.1207/FS15327965PLI1104_ 01

Deci, E. L., \& Ryan, R. M. (2008). Self-

Determination Theory: A macrotheory of human motivation, development, and health. Canadian Psychology, 49(3), 182-185. https://psycnet.apa.org/doi/10.1037/a0012801

Deci, E. L., Ryan, R. M., Gagne, M., Leone, D. R., Usunov, J., \& Kornazheva, B. P. (2001). Need staisfaction, motivation, and well-being in the work organizations of a former Eastern Block country. Personality and Social Psychology Bulletin, 27, 930-942. https://doi.org/10.1177\%2F014616720127800 2

Deci, E. L., Ryan, R. M., \& Williams, G. C. (1996). Need satisfaction and the self-regulation of learning. Learning and Individual Differences, $8(3), 165-183$.

http://dx.doi.org/10.1016/S10416080(96)90013-8

Deci, E. L., Vallerand, R. J., Pelletier, L. G., \& Ryan, R. M. (1991). Motivation and Education: The self-determination perspective. Educational Psychologist, 26(3 \& 4), 325 346. https://doi.org/10.1207/s15326985ep2603\&4_ 6

Elchardus, M. (Ed.). (1994). De school staat niet allen. Verslag van de commssie SamenlevingOnderwijs aan de Koning

Boudenwijnstichting. (The school doesn't stand alone. Report of the Commission SocietyEducation to the Koning Boudewijnstichting). Koning Boudewijnstichting-Pelckmans.

Fernet, C., Austin, S. p., Tre'panier, S.-G. v., \& Dussault, M. (2013). How do job characteristics contribute to burnout? Exploring the distinct mediating roles of perceived autonomy, competence, and relatedness. European Journal of Work and Organizational Psychology, 22(2), 123 - 137. https://doi.org/10.1080/1359432x.2011.632161

Fernet, C., Channa, J., \& Guay, F. (2017). What fuels the fire: Job- or task-specific motivation (or both)? On the hierarchical and multidimensional nature of teacher motivation in relation to job burnout. An International Journal of Work, Health \& Organisations, 31(2), 145-163. https://doi.org/10.1080/02678373.2017.130375 8

Fernet, C., Senécal, C., Guay, F., Marsh, H., \& Dowson, M. (2008). The Work Tasks Motivation Scale for Teachers (WTMST). Journal of Career Assessment, 16(2), 256 - 
279.

https://doi.org/10.1177/1069072707305764

Gagne, M., \& Deci, E. L. (2005). Self-

Determination Theory and work motivation. Journal of Organizational Behavior, 26, 331 362. https://doi.org/10.1002/job.322

Gillet, N., Vallerand, R. J., \& Lafreniere, M. K. (2012). Intrinsic and extrinsic school motivation as a function of age: the mediating role of autonomy support. Social Psychology Education, 15, 77-95. https://doi.org/10.1007/s11218-011-9170-2

Grolnick, W. S., \& Ryan, R. M. (1989). Parent styles associated with children's self-regulation and competence in school. Journal of Educational Psychology, 81, 143-154. https://doi.org/10.1037/0022-0663.81.2.143

Guay, F., Mageau, G., \& Vallerand, R. J. (2003). On the hierarchical structure of self-detremined motivation: A test of top-down and bottom-up effects. Personality and Social Psychology Bulletin, 29, 992 - 1004. https://doi.org/10.1177/0146167203253297

Guskey, T. R. (2002). Evaluating professional development. Corwin.

Hargreaves, A. (2000). Four ages of professionalism and professional learning. Teachers and Teaching: History and Practices, 6(2), 151182. https://doi.org/10.1080/713698714

Lafrenière, M.-A. K., Verner-Filion, J., \& Vallerand, R. J. (2012). Development and validation of the Gaming Motivation Scale (GAMS). Personality and Individual Differences, 53(7), 827-831. http://dx.doi.org/10.1016/j.paid.2012.06.013

Mallett, C., Kawabata, M., Newcombe, P., OteroForero, A., \& Jackson, S. (2007). Sport Motivation Scale-6 (SMS-6): A revised sixfactor Sport Motivation Scale. Psychology of Sport and Exercise, 8(5), 600-614. http://dx.doi.org/10.1016/j.psychsport.2006.12. 005

Martens, M. P., \& Webber, S. N. (2002). Psychometric properties of The Sport Motivation Scale: An evaluation with college varsity athletes from the U.S. Journal of Sport \& Exercise Psychology, 24(3), 254-270. http://dx.doi.org/10.1123/jsep.24.3.254

Opfer, V. D., \& Pedder, D. (2011). Conceptualizing teacher professional development. Review of
Educational Research, 81(3), 376-407. https://doi.org/10.3102/0034654311413609

Pelletier, L. G., Fortier, M. S., Vallerand, R. J., Tuson, K. M., Brière, N. M., \& Blais, M. R. (1995). Toward a new measure of intrinsic motivation, extrinsic motivation and motivation in sports: The Sport Motivation Scale (SMS). Journal of Sport \& Exercise Psychology, 17, 35-53. https://doi.org/10.1123/jsep.17.1.35

Pelletier, L. G., Rocchi, M. A., Vallerand, R. J., Deci, E. L., \& Ryan, R. M. (2013). Validation of the revised Sport Motivation Scale (SMSII). Psychology of Sport and Exercise, 14(3), 329-341. http://dx.doi.org/10.1016/j.psychsport.2012.12. 002

Ryan, R. M., \& Deci, E. L. (2017). SelfDetermination Theory: Basic psychological needs in motivation, development, and wellness. Guilford.

Ryan, R. M., \& Deci, E. L. (2019). Brick by brick: The origins, development, and future of SelfDetermination Theory. In A. J. Elliot (Ed.), Advances in motivation science, 6 (pp. 111156). Elsevier. https://doi.org/10.1017/9781108290876.016

Vallerand, R. J. (1997). Toward a hierarchical model of intrinsic and extrinsic motivation. Advances in Experimental Social Psychology, 29, 271-360. https://doi.org/10.1016/S00652601(08)60019-2

Vallerand, R. J., Pelletier, L. G., Blais, M. R., Brière, N. M., Sénécal, C., \& Vallières, E. F. (1992). Academic Motivation Scale: A measure of intrinsic, extrinsic and amotivation in education. Educational and Psychological Measurement, 52, 1003-1017. https://doi.org/10.1177\%2F001316449205200 4025

Vansteenkiste, M., Sierens, E., Soenens, B., Luyckx, K., \& Lens, W. (2009). Motivational profiles from a self-determination perspective: The quality of motivation matters. Journal of Educational Psychology, 101, 671-688. https://doi.org/10.1037/a0015083

Wigfield, A., \& Eccles, J. S. (2000). Expectancy -Value Theory of Achievement Motivation. Contemporary Educational Psychology, 25, 68 - 81. https://doi.org/10.1006/ceps.1999.1015 